\title{
Marcos legais como atos de currículo na formação profissional em educação física
}

RESUMO: O presente artigo tematiza a questão da evolução histórica dos modelos curriculares adotados nacionalmente pelo Ministério da Educação para a área de Educação Física. Para tanto, articula o debate contemporâneo de algumas correntes teóricas do campo curricular com os enunciados históricos de pesquisadores da Educação Física, na tentativa de alinhavar o entendimento de que os seus marcos legais, representados nas reformas do Estado, se constituíram nos principais atos de currículo que marcaram o cenário de tensões político-ideológicas desta área de conhecimento.

PALAVRAS-CHAVE: Educação Física. Formação Profissional. Diretrizes Curriculares.

\section{O Lugar de Onde Falamos}

O intuito deste breve ensaio é tecer algumas considerações, de caráter epistemológico, acerca do papel que determinados mecanismos legais, aqui representados por leis e diretrizes oriundas do poder público, exerceram no percurso histórico da formação profissional em Educação Física. Toma como ponto de partida as contribuições de alguns estudos históricos e curriculares, com âmbito na formação profissional, bem como dialogar e aproximar tais estudos às contribuições oriundas do campo curricular.

Inicialmente, gostaria de colocar a necessidade de explicitação de algumas terminologias, que tratamos no interior deste texto, tendo em vista o sentido pelo qual as mesmas serão tomadas. Não se trata de nenhuma reconceitualização ou teorização aprofundada. É apenas uma ressalva, para que os termos Marcos legais e atos curriculares não sejam tomados por uma acepção indesejada.

Primeiramente, caracterizamos o termo marcos legais como a ocorrência de resoluções e pareceres promulgados ao longo da história da Educação Física brasileira, e que deram conta de regulamentar o processo de gestão da formação profissional desta área de conhecimento dentro de padrões legais. Assim, o entendimento pelo qual tomarei o sentido dado às resoluções e pareceres aqui citados, os remeterá a um conceito que as englobará a uma idéia geral de marcos legais.

Em rota de convergência com esta compreensão, a evidência destes marcos como elementos da gestão da formação, em nosso olhar epistemológico, tomará emprestado o conceito de atos de currículo desenvolvido por Macedo (2004), para identificá-los
César Pimentel Figueiredo Primo Professor Assistente da Universidade Estadual do Sudoeste da Bahia Campus Jequié pimentelbaiano@terra.com.br

Fernando Reis do Espírito Santo Professor Assistente da Faculdade de Educação da UFBA. fres.nando@uol.com.br 
como mecanismos legais grávidos de um universo de intencionalidades do poder público, ou seja, como atitudes curriculares. Assim, em relação sinônima, estaremos falando da ocorrência de tais marcos como atos de currículo, ou como define o próprio autor, "[...] como construções socioculturais interessadas na formação, como atos epistemológicos, morais e políticos (que) podem cultivar o compromisso de trabalhar no intervalo, nas dobras, nas brechas, nas fissuras e tensões dessas ambivalências e contradições". (MACEDO, 2004, p.2)

Nesta perspectiva, a gestão da formação profissional, aqui tratada, engloba todos os elementos que possam envolver o universo de sentidos dessa expressão, sejam eles de qualquer natureza; cargo administrativo, docência, discência, eventos acadêmicos, documentos, legislações, etc. percebidos como fomentadores, ora intencionalmente, ora não, do processo de construção de uma possível identidade profissional do futuro egresso de uma graduação. Assim, o olhar epistemológico do autor supracitado nos autoriza a refletir no sentido de compreender os

[...] atos de currículo como parâmetros, diretrizes, referenciais, práticas de implementação de diretrizes, construções/reconstruções curriculares, normas de certificação etc, (que) se constituem de forma potente em regulação política, epistemológica, cultural e pedagógica da educação no Brasil nos últimos tempos [...] (MACEDO, 2004, p.3)

Este universo de considerações ilustra o cenário de complexidade e conflitos cotidianos que formam o palco de ocorrência onde marcos legais, como atos curriculares, compõem uma dimensão mais ampla e complexa dos mecanismos gestores de um currículo, este entendido como "[...] lugar de representação simbólica, transgressão, jogo de poder multicultural, lugar de escolhas, inclusões e exclusões, de uma lógica explícita ou clandestina, expressão da vontade de um sujeito ou imposição do próprio ato discursivo". (BERTICELLI, 1999, p. 160)

É neste cenário multifacetado, que inserimos a especificidade de um contexto, qual seja o da formação profissional nos cursos de licenciatura em Educação Física. Mais especificamente, partimos de um recorte da história desse processo que toma como ponto de reflexão acerca de seus mecanismos gestores de formação, exatamente os seus marcos legais. Assim entendemos que estes influenciam e são influenciados por demandas de diversas

186 R. Faced, Salvador, n.12, p.185-202, jul/dez. 2007 
ordens, segundo os interesses e jogos de forças daqueles que estão envolvidos, ou não, no processo educativo.

É ainda com Berticelli (1999, p.168) que situamos estes mecanismos gestores do currículo na formação profissional, como

[...] lugares em que se concede a palavra ou se toma a palavra no jogo de forças políticas, sociais e econômicas. [...] onde pode-se ler, assim, a estrutura social, as estratificações, o pensamento dominante, os interesses explícitos e implícitos do poder difuso, multipartite e multifacetado, polífono.

Assim, buscamos em nosso intento, as irregularidades das costuras da colcha de retalhos afirmada pela ótica do discurso oficial, ou quem sabe, audibilidade para novos discursos, novas interpretações, ou mesmo superação para o olhar míope e aligeirado que se convencionou utilizar para a caracterização do currículo a partir de decretos, que friamente constroem modelos de formação com base em iluminismos.

\section{O Sujeito Histórico a que nos Referimos}

O contexto sociopolítico que envolve a sociedade em determinado momento histórico é determinante para a caracterização dos modelos de políticas públicas que o Estado implementa para a governança de seus cidadãos. No campo educacional, especificamente, as políticas de gestão da formação profissional têm seguido trilhas, não raro, oriundas de medidas legais, erigidas nos gabinetes do Ministério da Educação. Geralmente, tais políticas têm tido um caráter instrumental e uma abordagem tecnocrática para a formação dos professores, caracterizada por pacotes governamentais, que orientam e determinam um modelo gerencial específico para o processo de formação profissional.

As universidades, como elementos fundamentais do conjunto de estratégias utilizadas para o processo de formação profissional, vêm acompanhando esta trajetória histórica ora como artífice, ora como objeto de tais políticas. Não raro encontraremos na literatura específica, menções às relações que estas guardam com diversas organizações da sociedade como um todo. Hardy e Fachin (1996), em estudo desenvolvido sobre a gestão estratégica de cinco grandes universidades federais do Brasil, colocam que esta relação determina valores profissionais que

R. Faced, Salvador, n.12, p.185-202, jul/dez. $2007 \quad 187$ 
guiam, motivam e controlam os membros de uma organização.

Com esse perfil, nossas universidades têm, em determinados contextos, fidelizado o construto universalista da filosofia positivista, na medida em que trabalha com categorias como ordem, equilíbrio, harmonia e progresso em sua organização e seu funcionamento (SANDER, 1995). Assim, o currículo dos cursos de formação tem sido uma das ferramentas potencializadoras dessas políticas.

Nesse contexto, a especificidade do nosso cenário de abordagem tem como palco o processo de formação profissional em Educação Física, compreendida historicamente a partir de quatro atos curriculares, de características legais, que marcaram a sua trajetória de decretos e resoluções. Com isso, buscamos caracterizar o papel que esses marcos legais tiveram na evolução histórica dessa área de conhecimento.

\section{$\mathrm{O} \mathrm{I}^{\mathrm{O}}$ ato de currículo}

Em meio à primeira era Vargas (1932-1945), o Brasil vivia um período marcado pelo exercício centralizador, controlador e ditatorial de um governo nacionalista e populista. O projeto eugênico de purificação da raça brasileira teve como marca inconteste, dessa fase da política nacional, a participação de militares e médicos higienistas. A Educação Física em meio a este projeto nacionalista prestou sua colaboração, na medida em que emprestou seus construtos teóricos e sua prática pedagógica, amplamente difundida nos meios escolares, para a edificação do ideal eugenista.

Com a promulgação da Constituição de 1937, a Educação Física passa a ser obrigatória nas escolas brasileiras, o que desperta no meio a necessidade de se pensar em modelos de formação, baseados em currículos a serem implementados em cursos superiores de Educação Física. (SOUZA NETO, 2002). Assim, nasce em 1939, com o Decreto-lei no 1212, de 17 de abril de 1939, que cria a Universidade do Brasil (UB), a Escola Nacional de Educação Física e Desportos (ENEFD). Podemos dizer que aí reside a primeira experiência em nível nacional de um currículo de formação na área.

O que se observa nos primórdios da constituição histórica da área de Educação Física, como em quase todas as áreas do conhecimento, que foram objetos de políticas governamentais nesta etapa do modo de produção capitalista, é o vínculo estreito que a 
escola estabeleceu com o Estado ao assumir papéis relativos à normatização das relações sociais. Ou como caracteriza Ferretti (2002), relações marcadas entre o Estado e a ciência com vistas à produção de conhecimentos que lhe são mutuamente vantajosos, estabelecendo uma relação de interdependência entre educação e trabalho.

Assim, conforme nos ilustra Bercito (1996, p. 51)

O projeto relativo à Educação Física no período tinha, pois, um vetor dirigido para o coletivo, expresso no nacional. Concebida a nação como um vir-a-ser e a nacionalidade brasileira como algo a ser edificado a Educação Física teria, pois, aí o seu papel. Sua prática estendida ao conjunto da população seria capaz de a partir do investimento feito sobre o indivíduo, contribuir para transformar o povo e a sociedade. Procedendo a uma regeneração física, mas também moral do povo brasileiro, estaria trabalhando ativamente para construir uma nacionalidade vigorosa.

Este vínculo, parece-nos estar presente de forma marcante no interior da organização das disciplinas no currículo de formação dos professores de Educação Física, desse período. Grunenvaldt (1997, p. 136 apud PIRES, 2006, p. 184), ao fazer uma análise da proporcionalidade das disciplinas do curso da ENEFD, arremata:

Diante dessa proporcionalidade constatada no currículo e pelo número de cadeiras que dependiam da ciência mãe, a biologia, e o número de cadeiras que tratavam do conhecimento técnico-desportivo, entendemos que a preocupação da ENEFD era a formação de um homem biologizado.

Portanto, nesse seu primeiro ato curricular, houve na Educação Física uma preocupação direta com o corpo docente de seus futuros formadores. Numa dúbia acepção, pode-se inferir, inclusive, que a preocupação residia tanto na ordenação pedagógica de um tipo de conhecimento que se tornava aparentemente importante para o modelo industrial ao qual o país se adequava, quanto ao perfil físicobiológico daqueles que colocariam exemplo ao comportamento motor dos escolares. Não é à toa que a ginástica, oriunda das casernas, foi escolhida como referência e justificativa para a melhoria da saúde, conferindo ao corpo operário as qualidades necessárias às demandas históricas do Brasil republicano.

Soares (1997, p.8), em seus estudos históricos sobre a relação entre a ginástica e a Educação Física, nos auxilia nessa compre- 
ensão ao alertar sobre a necessidade que se tomou neste período histórico de se construir uma imagem do corpo educado e adequado às demandas prementes, visto que "[...] corpos que se desviam dos padrões de uma normalidade utilitária não interessam".

E para tal tarefa, parece-nos que a competência profissional estava intimamente relacionada à capacidade de execução das atividades propostas.

Os professores/as das cadeiras de ginástica rítmica, de Educação Física geral, de desportos aquáticos, de desportos terrestres individuais, de desportos terrestres coletivos e de desportos de ataque e defesa eram admitidos mediante contrato que versava a não possibilidade de ingresso com idade superior a 35 anos, nem permanência no exercício da função depois dos 40 anos de idade. (PEREIRA FILHO, 2005, p. 56)

Assim, este primeiro ato curricular de legislação da área vigorou como referência na formação do profissional da Educação Física até o final da década de 60 e advogou a formação em várias especialidades: Instrutor de ginástica (professoras primárias), Instrutor de ginásticas, Professor de Educação Física, Técnico em massagem e Técnico desportivo. Com exceção do curso para professores, que era integralizado em dois anos, os demais eram concluídos em apenas um ano.

\section{$\mathrm{O} 2^{\circ}$ ato de currículo}

Trinta anos depois, com a edição do Parecer n. 894/69 e da Resolução n. 69, de 06 de novembro de 1969, do Conselho Federal de Educação (CFE), aprova-se no Brasil o segundo marco legal de currículo para a formação dos profissionais de Educação Física. Este segundo modelo curricular configura-se legalmente como a instrução de um currículo mínimo para a integralização da formação, tendo em vista o surgimento e a expansão dos cursos na área, e a necessidade de se equalizar o problema da competência do exercício profissional entre os múltiplos técnicos desportivos e professores de Educação Física, oriundos de formulação de 1939.

Esta proposta pode ser interpretada como um avanço no que diz respeito ao currículo prescrito, na medida em que passou a reconhecer a necessidade de um conhecimento mínimo de área específico para o exercício profissional, mesmo porquê "... as escolas não estavam aparelhadas para manter cursos regulares das muitas especialidades existentes no país, não atendendo, portan-

190 R. Faced, Salvador, n.12, p.185-202, jul/dez. 2007 
to, à demanda social nem na quantidade, nem na qualidade". (PEREIRA FILHO, 2005, p. 57)

Essa proposta curricular não estava absolutamente preocupada em fazer qualquer tipo de questionamento mais radical relativo aos arranjos educacionais existentes, às formas hegemônicas de conhecimento ou, de modo mais geral, à forma social dominante. Para Pereira Filho (2005), um exemplo marcante desse rearranjo social para a manutenção do status quo foi a negativa do Conselho Federal de Educação à proposta apresentada no Parecer 894/69, ao negar na formação educacional dos futuros professores de Educação Física a matéria Sociologia.

Este ato curricular, gerado de dentro das engrenagens de uma ditadura militar, assume contornos claros de contenção ao movimento libertário que incendiava a juventude universitária da época. Na Educação Física ocorre uma suspeita divisão entre aqueles que fazem política e aqueles que praticam esporte. Ao passo que os diretórios acadêmicos foram desmobilizados, as associações atléticas foram entusiasticamente incentivadas. (MELO, 1997)

Administradas em 1800/horas/aula esta perspectiva curricular abrangia duas formações: Professor de Educação Física e Técnico Desportivo, que poderiam ser cursados concomitante ou separadamente. Constata-se neste período que a esportivização do fazer pedagógico do professor, mesmo que circunscrita ao universo da escola, concedeu um predomínio de uma visão bio-fisiológica da Educação Física nos meios acadêmicos até o final da década de 70 e início dos anos 80.

\section{$\mathrm{O} 3^{\circ}$ ato curricular}

O palco de ocorrência do novo marco legal que se instala na Educação Física brasileira é caracterizado pelo aprofundamento da ambivalência conceitual que marcou o desenvolvimento do modelo curricular passado. Fruto da efervescência pela qual passava o Brasil neste período, territórios foram demarcados. De um lado, a influência dos movimentos sociais organizados em partidos, sindicatos e movimentos populares na luta pela reconstituição das liberdades roubadas pelos anos de chumbo da ditadura militar, que agregada ao retorno de renomados educadores do exílio, insuflou as produções intelectuais do país, estabelecendo verdadeiras crises ${ }^{1}$ epistemológicas em determinadas áreas do conhecimento. O surgimento de livros, ensaios e teorizações críticas neste período 
conceitual e/ou da visão de mundo da teoria, e vivenciadas interjubjetivamente pelos sujeitos concretos e históricos envolvidos.

(2) Os termos contra-hegemonia e contra-esfera pública são aqui utilizados no sentido dado po Giroux e McLaren (2000, p. 132) dizem respeito a construção de esferas públicas alternativas implicam um entendimento mais político, mais teórico e mais crítico. não só da natureza da dominaça. ras também do tipo de oposiço ativa que deveria engendrar.

(3) Este documento foi elaborado em julho de 1984 por 12 professores de Educacão Física com reconhecida experiência na área, portadores de várias tendências

político-ideológicas, uns defensores

da Universidade Pública eutros

privatistas, todos indicados por

dirigentes da Federação Brasileira

das Associaçōes de Professores de

Educação Física (FBAPEF) e das

Associações de Professores de

Educaçãó Física (APEFS). Para a

redação final do documento. a

negociação entre estes diferentes

perfis de redatores chegou as er mediada por votação de propostas. (FARIA JUNIOR, 2001) colocam em xeque o pensamento e a estrutura educacional tradicionais e nesse contexto estava também o currículo, agora afetado por atos não formais, derivados de um exercício marginal contrahegemônico, orientado para a formação de contra-esferas públicas. ${ }^{2}$

De outro lado, fatias significativas dos profissionais da área reclamavam a ênfase dada nos cursos de formação ao ensino de conteúdos com características predominantemente pedagógicas, voltadas para a licenciatura. Os profissionais inseridos no contexto do mercado exigiam uma postura diferenciada tanto do ponto de vista didático-pedagógico como no que tange às habilidades técnicas dos professores formados nessa perspectiva curricular. (SOUZA NETO, 2002, p. 04) Para alguns pesquisadores da temática, esta banda da Educação Física foi responsável pelo discurso mercadológico da formação profissional.

Os privatizas esmeravam-se em apresentar pesquisas enviesadas e sem representatividade amostral para argumentar que a atuação preferencial do professor de educação física não era mais a escola. [...] A corrente privatista, que já lutava pela transformação da educação física em "profissão liberal", adotara a estratégia de fragmentação da profissão, na época travestida de "habilitações". (FARIA JUNIOR, 2001, p. 22)

Neste cenário de embates conceituais sobre a perspectiva desejada para os formados da área, o discurso dos chamados grupos progressistas da Educação Física, que apesar de também insatisfeitos com os desígnios do modelo curricular anterior, não se afinava com a estratégia de saída para a formação profissional pela via exclusiva de adaptação aos ditames do mercado de traba1ho, como queriam os privatistas. A proposição de extinção do currículo mínimo defendida por estes setores distanciava-se do perfil de especialista habilitado em demandas de mercado. Ao contrário, propunha a formação de um professor generalista para atuação em sistemas formais e não-formais de ensino, licenciados a partir de uma perspectiva humanista.

No bojo dessas divergências conceituais é que se insere a Carta de Belo Horizonte ${ }^{3}$ como uma marca histórica importante desse ato de currículo. Construída a partir das manifestações oriundas de ambos os lados, este documento apresenta-se como numa referência histórica para a constituição das engrenagens legais que marcaram este ato curricular. A Carta, como síntese do debate de área, apresentou à Secretaria de Educação Física e Desportos do 
Ministério da Educação (SEED/MEC) os sensos e contra-sensos da Educação Física brasileira. Para Faria Júnior (2001, p. 19), a Carta "[...] faz uma bem-sucedida avaliação da educação física da época, com suas contradições, avanços e retrocessos, retrata o embate entre os defensores da escola pública e os privatistas, e a luta pela organização política dos professores".

Dessa forma, este terceiro ato de currículo da cena sociopolítica e cultural dos marcos legais da Educação Física é marcado por uma intensa crise do e no conhecimento de área produzido. A idéia de currículo como rol de disciplinas dos programas estatais, como a idéia de currículo mínimo, sofre grande revés no meio intelectual, na medida em que ao se desnudar as agruras sociais resultantes da governança militar, parte das produções nacionais passa a imaginar um currículo voltado para as minorias sociais usurpadas de seus direitos.

Os estudiosos dessa época também trabalham a questão da adequação dos conteúdos aos alunos. Fez-se a análise que se faz, hoje, dos silenciamentos e dos modos e métodos de provocá-los. A tendência mais corrente é de adotar um currículo crítico ou, ao menos, uma postura crítica diante das questões curriculares. (BERTICELLI, 1999, p. 171)

E é assim que quase 20 anos depois do segundo currículo oficial, com a implementação da Resolução $n^{0} 03$, de 16 de junho de 1987 do CFE, influenciada pela Carta de Belo Horizonte, que a Educação Física constrói as novas bases legais para a sua formação profissional, sugerindo a integralização do curso em duas habilitações: Licenciado e/ou Bacharel em Educação Física. Este ato curricular é marcado por inovações, até certo ponto avançadas, como a concessão às Instituições Superiores de Educação Física (ISEF) de autonomia para a composição curricular da formação do perfil profissional desejado.

Os cursos criados nessa época apresentaram-se como vanguarda da área, visto o frescor da temática na elaboração de seu currículo, dando, inclusive, uma maior atenção à formação do licenciado, com "[...] uma preocupação maior com o curso de licenciatura na Resolução 03/87 em relação à Resolução 69/69, sendo um ponto de ampliação no discurso da área exposto nos documentos". (MENDES, 2004, p. 04)

Tojal (2004, p.1) complementa essa idéia de avanço ao afirmar que "[...] o advento da Resolução MEC/CFE 03/87, passou a 
proporcionar a liberdade para que as Instituições de Ensino Superior (IES) organizassem seus próprios projetos pedagógicos, quebrando assim com a prática da definição e estabelecimento de currículo mínimo para cada profissão".

Por fim, esta idéia de autonomia e liberdade é também compartilhada por Pereira Filho (2005), que entende ter sido este marco legal responsável pela preparação de um profissional apto a lidar com a fragmentação do mercado de trabalho, na medida em que possibilitaria a ampliação da visão de realidade social, política e econômica do país, com uma formação mais generalista.

Com o advento deste novo aparato legal, o paradigma instalado, além de ampliar a carga horária de 1800 horas/aula para 2800 horas/aula, flexibiliza a estrutura nuclear de conhecimentos mínimos obrigatórios, concedendo às instituições o direito de montar seus projetos pedagógicos e fluxogramas de curso divididos em duas partes programáticas, a Formação Geral e o Aprofundamento de Conhecimentos, sem o aprisionamento das disciplinas obrigatórias do currículo mínimo.

No entanto, esta perspectiva de avanço não pode ser encarada por um prisma linear. O cenário estabelecido pela nova regulamentação acabou por calcificar o velho dilema da área ao estabelecer a formação bifurcada em licenciatura e bacharelado. Porém, reconhecemos que esta mão dupla acomodou parte da tensão estabelecida na medida em que acabou adaptando a formação profissional às possibilidades de exercício da profissão, conforme se apresentavam no mundo do trabalho.

A pressuposta acomodação dos diversos elementos compôs a colcha de retalhos que estruturou os atos curriculares da formação profissional nesta área. E como os marcos legais se apresentam como um desses componentes, pensamos que a despeito de todo avanço proclamado pela resolução, é possível se pensar em autoritarismos, na medida em que a liberdade preconizada no artifício desta lei, concede vigiadamente, e não autoriza, a reinvenção da realidade. Pode-se dizer de um pré-potente ato de currículo fundado num globalismo iluminado e tecnocrata. (MACEDO, 2004, p.5)

Essa pré-potência se consubstancia em propostas formativas vindas em geral de uma concepção de currículo projetada (de longe, de fora e do alto), mesmo que a flexibilidade e os modelos de reflexibilidade estejam atualmente compondo muitas dos discursos e cenários curriculares de forma veemente.

194 R. Faced, Salvador, n.12, p.185-202, jul/dez. 2007 
Nessa perspectiva, entendemos que a abertura para a formulação e elaboração dos currículos de formação, circunscritos às demandas regionais de cada instituição de ensino superior, concedida pela resolução, acabou tomando tons de uniformidade, na medida em que esta flexibilização permitiu, também, a calcificação de discursos oriundos do modelo anterior, abrindo perigosas possibilidades de aproximação da área com determinadas demandas emergentes do mercado. Assim, Faria Júnior (2001) aponta como conquistas do bloco privatista o apoio do Estado à proliferação de cursos privados, por meio da destinação de verbas; a criação dos cursos de bacharelado, delimitando claramente o papel mercadológico deste; e a regulamentação da profissão por meio da criação de conselhos profissionais, bem como do código de ético da profissão.

Daí nos salta a sensação de que este ato curricular consolida avanços de ambas as partes. Ao passo que garante uma formação generalista e humanística para o egresso, abre alas para a formatação do bacharel em consonância com os ditames do mercado.

\section{$\mathrm{O} 4^{\circ}$ ato de currículo}

Em princípio, a divisão final da formação em duas habilitações parece ter sido uma forma de acomodação das brigas internas da Educação Física. No entanto, parece ter havido uma espécie de supremacia do ideário crítico, oriundo daqueles que defendiam uma formação generalista, voltada prioritariamente para o setor público de ensino, via licenciatura, em detrimento do grupo que defendia seu quinhão de poder ao garantir a formação pela via do bacharelado. Espírito Santo (2004, p.87), quanto a isso, ressalva:

Na correlação de forças o CONFEF vem tentando afirmar que a criação do bacharelado foi fundamentalmente, uma resposta aos argumentos de que a formação do licenciado não vinha atendendo ao desenvolvimento das qualificações e das competências necessárias à intervenção do profissional nos diversos campos de trabalho não-escolar.

Portanto, o que parecia de início ser uma trégua na briga pela concepção final do egresso, se delineou mais tarde numa guerra fria travada nos bastidores, onde os setores voltados para a emergência dos desígnios do mercado foram paulatinamente construindo novas estratégias de resgate desse debate para a cena pública.

R. Faced, Salvador, n.12, p.185-202, jul/dez. 2007195 
Como fruto desse movimento estratégico nasceu em 1998, com a promulgação da Lei 9696, o sistema CREF/CONFEF (Conselhos Regionais de Educação Física e o Conselho Federal de Educação Física) e com ele o mercado de atuação e o profissional de Educação Física. Sobre o primeiro a Lei estabelece: "Art. 10 - O exercício das atividades de Educação Física e a designação de Profissional de Educação Física é prerrogativa dos profissionais regularmente registrados nos Conselhos Regionais de Educação Física". (BRASIL, 1998, p.1)

E ao reservar seu espaço de atuação, designa, em seguida, as suas competências profissionais:

Art. $3^{\mathbf{0}}$ - Compete ao Profissional de Educação Física coordenar, planejar, programar, supervisionar, dinamizar, dirigir, organizar, avaliar e executar trabalhos, programas, planos e projetos, bem como prestar serviços de auditoria, consultoria e assessoria, realizar treinamentos especializados, participar de equipes multidisciplinares e interdisciplinares e elaborar informes técnicos, científicos e pedagógicos, todos nas áreas de atividades físicas e do desporto.

Assim, ao passo em que o ato anterior se caracterizou pela investida predominante dos intelectuais críticos para a sua ocorrência, este é marcado pela resistência dos mesmos, na medida em que o demonizam por apresentar sintomas de rendição da formação profissional em Educação Física aos ditames das políticas neoliberais da economia de mercado globalizada, sob dois aspectos: a garantia da reserva de mercado por meio da regulamentação do exercício profissional e a potencialização da formação por demanda, onde o mercado opera como parâmetro de referência para a formação, baseada apenas na lógica da venda da força de trabalho.

O retorno progressivo de setores e vozes oriundas do modelo sustentado pela Res. 69/69, que se aproveitando do desgaste paulatino dos discursos críticos, possibilitou a ocupação de trincheiras vazias, deixadas pelas lutas monocromáticas do Brasil pósditadura. O discurso focado exclusivamente nas preocupações com as minorias desfavorecidas, social e economicamente, perdeu espaço para questões pragmáticas de inserção do egresso da licenciatura na realidade objetiva, preocupadas com as novas demandas do mercado, principalmente nos países emergentes ávidos por se globalizarem, ou, como dizem Carlson e Apple (2000) por-

196 R. Faced, Salvador, n.12, p.185-202, jul/dez. 2007 
ta-vozes de discursos pós-modernos ${ }^{4}$ de quebra ou ruptura com o passado.

A pressuposta ineficiência da retórica crítica em fornecer subsídios pragmáticos para a resolução dos problemas sociais, inclusive pela via da formação profissional, abriu alas para a ocorrência de fenômenos e práticas contestadas em décadas passadas. Para Giroux e McLaren (2000, p. 129), uma série de elementos contribuiu para a formatação dessa amálgama de vozes.

[...] os educadores radicais permaneceram atolados em um discurso crítico que associa as escolas basicamente às relações sociais de dominação; [...] o lamentável desta postura foi o fato de ter impedido que os educadores de Esquerda desenvolvessem uma linguagem pragmática na qual pudessem teorizar para as escolas. Em vez disso, os educadores radicais teorizaram sobre as escolas.

E é no vácuo desse momento histórico, que possibilita a ascensão de setores tradicionais da Educação Física brasileira, que se desenha o palco deste ato curricular, que se corporifica a partir dos trabalhos elaborados pela comissão de especialistas da Secretaria de Ensino Superior do Ministério da Educação (SESu/MEC). Esta se imbui de formular uma proposta para as novas diretrizes curriculares da Educação Física, orientadas programaticamente pelo Ministério da Educação, no sentido de "[...] permitir uma flexibilidade da construção dos currículos plenos, privilegiar áreas de conhecimento em vez de disciplinas e contemplar diferentes formações e habilitações para cada área do conhecimento" (ESPÍRITO SANTO, 2004, p. 84).

Essa flexibilidade e abertura caracterizam a encenação do presente ato curricular como uma legislação tatuada pelo aparthaid profissional. Mecanismos legais como diretrizes, resoluções e pareceres deram conta de separar o destino final da formação em dois caminhos. De um lado, amparados pelas Resoluções n. 01 e 02/02 do Conselho Nacional de Educação do MEC, os licenciados, responsáveis pelo exercício profissional no âmbito escolar. De outro, ancorados pela Resolução n. 07/04 do mesmo órgão, os graduados, antigos bacharéis, que passam a ter regulamentado seu exercício profissional, agora distinto legalmente do ofício de professor.

No contexto atual, esta divisão assemelha-se muito àquela descrita em seu segundo ato curricular. No entanto, agora, de um
(4) Para Carlson e Apple (2000). o termo pós-modernidade refere-se ao reconhecimento de que se trata de uma época sinalizadora de uma parciais, contraditórias e praticas coun que de certa forma estendem os projetos modernistas [...] De um ponto de vista crítico, essas mudanças não são inerentemente boas ou más. Ao contrário, são ambiguas nas suas implicações e abertas em suas possibilidaes. Portanto, dependem muito dos usos que lhes são dados. (CARLSON; APPLE, 2000, p. 17)

R. Faced, Salvador, n.12, p.185-202, jul/dez. $2007 \quad 197$ 
lado aqueles que defendem a chamada empregabilidade, o vínculo direto da formação como resultado das demandas de mercado. Um profissional on-demand sintonizado com as necessidades de consumo, com o bem-estar de quem pode ter e não, necessariamente, de quem precisa. De outro, aqueles que, preocupados com uma formação emancipatória, ainda trazem consigo as marcas das lutas da década de 80 e as dúvidas sobre a superação das antigas formas de enfrentamento.

Parece-nos, então, que este marco legal decreta um afastamento conceitual que nega o compartilhamento de saberes nos mais diversos nichos de atuação da profissão. Este painel sinaliza para um sistema dual de formação pautado numa antiga rivalidade do interior da área, marcada pela atuação no âmbito escolar e não-escolar. Essa separação, para além de resolver o antigo problema epistemológico da Educação Física, qual seja o do seu objeto de estudo, tenciona o debate sobre a formação profissional na medida em que coloca à frente das instituições formadoras a responsabilidade sobre que perfil de seus futuros egressos. Assim, parece-nos perigosa a construção de um novo paradigma de formação pautado exclusivamente nas características e demandas dos ambientes de atuação profissional, sob pena de alienarmos a produção acadêmica das universidades exclusivamente aos anseios e necessidades do mercado produtivo.

(5) Esta publicação é o mecanismo oficial de divulgação e comunicação do CONFEF junto a seus associados e a sociedade em geral. Pode ser acessada no site http:// www.confef.org.br.

\section{Acenos Conclusivos}

A narrativa social como se apresenta nos sugere que o processo dessa formação profissional toma contornos irreversíveis, na medida em que parece se afirmar os ditames de uma economia excludente. Jorge Steinhilber, presidente do Conselho Nacional de Educação Física (CONFEF), baseado nos fundamentos da legislação atual, em recente artigo da Revista Educação Física ${ }^{5}$, sacramenta:

A LICENCIATURA: a formação de professores que atuarão nas diferentes etapas e modalidades da educação básica, portanto para atuação específica e especializada com a componente curricular Educação Física.

O BACHARELADO: (inicialmente designado de graduação) qualificado para analisar criticamente a realidade social, para nela intervir por meio das diferentes manifestações da atividade física e esportiva, tendo por
\end{abstract}

198 R. Faced, Salvador, n.12, p.185-202, jul/dez. 2007 
finalidade aumentar as possibilidades de adoção de um estilo de vida fisicamente ativo e saudável, estando impedido de atuar na educação básica. (STEINHILBER, 2006, p. 20)

Essa lógica estabelecida do licenciado como professor escolar e do graduado como profissional do mercado, insinua-nos a emergência de se instituir compreensões mais aprofundadas destes atos curriculares. Para Nozaki (2005), a Educação Física brasileira sempre esteve a serviço do Estado, às vezes de forma consciente por representar diretamente projetos históricos de dentro das suas engrenagens, outras tanto por força de leis e resoluções, utilizando-a como um instrumento de dominação e alienação. Para o autor, o reordenamento atual desta área do conhecimento, motivada por seus aspectos legais, é marcado por um movimento de contradição na medida em que serve à recomposição do capital e desvaloriza-se como forma de trabalho.

Também, em caráter de alerta, o documento final do XII Encontro da Associação Nacional pela Formação dos Profissionais da Educação (ANPOFE, p.8) sinaliza para a necessidade de se atentar para a atual configuração das políticas de orientação da formação profissional patrocinadas pelo Estado. Um dos aspectos veementemente pontuados no documento diz respeito ao "aligeiramento da formação do profissional de educação, via propostas neo-tecnicistas que pretendem transformá-lo em um "prático" com competência para the dar exclusivamente com os problemas concretos de sua prática cotidiana" (ASSOCIAÇÃO NACIONAL PELA FORMAÇÃO DOS PROFISSIONAIS DA EDUCAÇÃO, 2004, p. 08). Parece-nos que esta tem sido a tônica do reordenamento legal da Educação Física que se desdobrará, provavelmente, em propostas curriculares de formação.

Portanto, a compreensão dessa ambivalência como dada, ou como conseqüência natural das metamorfoses sociais, é conformista, perigosa e omissa. A necessidade de reformulações dos cursos de Educação Física, que este quarto ato curricular de natureza legal impõe às IES brasileiras, convoca seus profissionais a sentarem-se à mesa de negociações para tratar daquilo que de fato interessa no processo: o perfil identitário da nova geração de egressos que se colocará â disposição de uma sociedade multicultural, com diversos de seus paradigmas em crise, cheia de perguntas e carente de respostas. 
Acompanha essa perspectiva a crença de que em realidade as reformas, com as quais vivemos até agora, têm o caráter neoconservador das tecnocracias liberais, em alguns casos com certos toques pós-modernos escamoteadores. Tal situação nos autoriza a dizer que as inovações conceituais e os atos de currículo, daí advindos, não tocaram as práticas educativas em termos da construção de uma educação tensionada no e pelo plural enquanto concepção politizada na vontade de justiça social. (MACEDO, 2004, p. 4)

Entendemos que a via do pronto atendimento aos requisitos do mercado, sob o argumento da sobrevivência e da empregabilidade possível, talvez seja o caminho mais distante para a retomada e reorientação dos sonhos e das utopias visualizadas em nome de uma possível justiça social.

Uma outra observação que nos cabe fazer neste momento é acerca do poder que normas e leis exercem sobre a sociedade como formuladores de atitudes sociais. Regra geral, apresentamse como irrevogáveis e imparciais. A história dos marcos legais na Educação Física tem nos mostrado que apenas mais recentemente movimentos e levantes organizados se materializaram como atos vivos de currículo no encalço de mudanças estruturais na formação da área.

Assim, fica-nos uma indagação final: Nesse cenário, e tendo como ponto de partida a configuração legal que orienta as atuais formulações curriculares dos cursos de Educação Física, esta área de conhecimento está mais próxima de se identificar afirmativamente com as distorções sociais do atual estágio do modo de produção capitalista ou de apontar formulações emancipatórias, parceiras de novos projetos e novas utopias sociais?

Entendemos que a nossa capacidade de formulação de novos atos curriculares, a partir de uma escuta mais sensível e menos engessada, é que poderá nos habilitar para a construção de possíveis saídas para o impasse que ora identificamos no núcleo do processo de formação profissional na Educação Física brasileira.

Entre a necessidade de reconhecimento de que algumas verdades apresentadas pelo atual modelo societal precisam ser avaliadas e a urgência de se desmistificar a mentira de que estamos no fim da história de nosso processo civilizatório, encontra-se uma tensão que se caracteriza pela busca de respostas fora da ordem iluminista de razão, ciência, racionalidade e progresso constante (SILVA, 1999), pela qual fomos habituados a pensar o mundo.

200 R. Faced, Salvador, n.12, p.185-202, jul/dez. 2007 
Legal limits as actions of curriculum in the professional formation in Physical education

ABSTRACT: The present article brings as theme the subject of the historical evolution of the models curriculares adopted nationally by Ministry of Education for the area of Physical education. For so much it articulates the contemporary debate of some theoretical currents of the field curricular with the researchers' of the Physical education historical statements, in the attempt to tack the understanding that their legal marks, acted in the reforms of State, they were constituted in the main curriculum actions that marked the scenery of political-ideological tensions of this knowledge area.

KEYWORDS: Curriculum guidelines. Job training. Physical education and training.

\section{Referências}

ASSOCIAÇÃO NACIONAL PELA FORMAÇÃO DO PROFESSORES DA EDUCAÇÃ (ANFOPE). Políticas públicas de formação dos profissionais da Educação: desafios para as Instituições de Ensino Superior. [Brasília], 2004. Documento final do XII Encontro Nacional. Brasília, 2004.

BERCITO, S. D. R. Educação Física e construção nacional (1932-1945). In: FERREIRA NETO, A. (Org.). Pesquisa histórica na educação física brasileira. Vitória: Centro de Educação Física e Desportos, UFES, 1996. p. $145-160$

BERTICELLI, I. A. Currículo: tendências e filosofia. In: VORRABER, Marisa Costa. O currículo no limiar do contemporâneo. 2. ed. Rio de Janeiro: DPEA, 1999.

BRASIL, 1998. Lei no 9.696, de 01 de setembro de 1998. Dispõe sobre a regulamentação da Profissão de Educação Física e cria os respectivos Conselho Federal e Conselhos Regionais de Educação Física. Brasília, 1998. Disponível em: <http://www.prolei.inep.gov.br> Acesso em: 29 abr. 2007.

CARlSON, D.; APPLE, M. W. Teoria educacional crítica em tempos incertos. In: HYPOLITO, A. M. (Org.). Educação em tempos incertos. Belo Horizonte: Autêntica, 2000.

ESPÍRITO SANTO F. R. Políticas de reformulação curricular em educação física no Brasil. 2004. Tese (Doutorado em Educação) Pontifícia Universidade Católica de São Paulo, São Paulo, 2004.

FARIA JÚNIOR, A. G. Reflexões sobre a educação física brasileira :a carta de Belo Horizonte. Revista Brasileira de Ciência do Esporte, São Paulo, v. 23, n. 1, p. 19-31, set. 2001.

FERRETTI, C. J. A pedagogia das competências: autonomia ou adaptação? Educação e Sociedade, v. 23, n. 81, p. 299-306, 2002.

GIROUX, H. A.; MCLAREN, P. Formação do professor como uma contra-esfera pública: a pedagogia radical como uma forma de política cultural. In: MOREIRA, A. F. B.; SILVA, T. T. (Org.). Currículo, cultura e sociedade. Tradução de Maria Aparecida Batista. 4. ed. São Paulo: Cortez, 2000. 
HARDY, C.; FACHIN, R. Gestão estratégica na universidade brasileira: teoria e casos. Porto Alegre: Ed. da UFRGS, 1996.

MACEDO, Roberto Sidnei. Ética do debate, atos de currículo e intercrítica.. Educação e Linguagem, São Paulo, v. 1, n. 1, p. 90-104, 2004.

MELO, V. A. Escola Nacional de Educação Física e Desportos: um estudo histórico, a "história" de um estudo e o estudo da história. In: FERREIRA NETO, A. (Org.). Pesquisa histórica na educação física. Vitória: UFES, Centro de Educação Física e Desportos, 1997. v. 2, p. 33-60.

MENDES, C. L. Reforma curricular de um curso superior: relações de poder e busca de legitimidade. 2004. Disponível em < http://www. educacaoonline.pro.br/reforma_curricular.asp > Acesso em: 4 dez. 2004.

MOREIRA, A. F. B. A crise da teoria curricular crítica. In: VORRABER, Marisa Costa. O currículo no limiar do contemporâneo. 2. ed. Rio de Janeiro: DPEA, 1999.

NOZAKI, H. T. Educação Física: limites da formação e exercício profissional. FIGUEIRÊDO, Z. C. C. (Org.). Formação profissional em educação física e o mundo do trabalho. Vitória: Faculdade Salesiano, 2005.

PEREIRA FILHO, E. Educação Física: limites da formação e exercício profissional. FIGUEIRÊDO, Z. C. C. (Org.). Formação profissional em educação física e o mundo do trabalho. Vitória: Faculdade Salesiano, 2005. v.1, p.47-69.

PIRES, R. G. Formação profissional em educação física no Brasil: suas histórias, seus caminhos. Revista da FACED, Salvador, n. 10, p. 179193, ago. 2006.

SANDER, B. Gestão da Educação na América Latina: construção e reconstrução do conhecimento. São Paulo: Autores Associados, 1995.

SILVA, T. T. Documento de identidade: uma introdução às teorias de currículo. Belo Horizonte: Autêntica, 1999.

SOARES, Carmen Lúcia. Imagens do corpo "educado": um olhar sobre a ginástica no século XIX. In: FERREIRA NETO, A. (Org.). Pesquisa histórica na educação física. Vitória: Centro de Educação Física e Desportos, UFES, 1997. v. 2, p. 05-32.

SOUZA NETO, Samuel de. A formação do profissional de educação física no Brasil: uma história sob a perspectiva da Legislação Federal no século XX. In: CONGRESSO BRASILEIRO DE HISTÓRIA DA EDUCAÇÃO FÍSICA, ESPORTE, LAZER E DANÇA, 8., 2002, Ponta Grossa, PR. As ciências sociais e a história da educação física, esporte, lazer e dança. Anais... Ponta Grossa, PR: Universidade Estadual de Ponta Grossa, 2002.

STEINHILBER, J. Licenciatura e/ou bacharelado: opções de graduação para intervenção profissional. Revista Educação Física, Rio de Janeiro, ano 6, n. 19, p. 19-20, mar. 2006.

TOJAL, J. B. A. G. Diretrizes curriculares: um pouco da história. 2004. Disponível em: < http://www.confef.locaweb.com.br >. Acesso em: 04 dez 2004. 